\title{
A postscript to "Peak P"- an agronomist's response to diminishing $P$ reserves
}

\author{
P.S. CORNISH \\ The University of Western Sydney \\ p.cornish@uws.edu.au
}

\begin{abstract}
'Peak P' analysts stress that rock phosphate (RP) production will decline and prices rise long before reserves run out, interpreting sharp price rises in 2007/2008 as a signal of Peak P and a looming crisis. We now know that the price spike had little to do with $\mathrm{P}$ reserves and that RP production should meet rising demand for the next $30+$ years, with only modest rises in fertiliser costs. More recent 'Peak P' analyses and other forecasts have agreed that around half the global stock of economically minable RP will be depleted by midcentury, leaving little for the $22^{\text {nd }}$ century without major RP discoveries and reduced use of RP-based fertiliser. (Stop Press: IFDC in September said reserves may be $4 \mathrm{x}$ previous estimates but gave no thorough revision of reserve life.) Although forecasting methods are hotly debated and data questioned, the real debate surrounds (i) the geo-politics of supply and (ii) confidence in finding new high-grade reserves or new technology to access lower-grade reserves, albeit at rising financial and environmental cost. Although the high stakes make a case for reducing long-term demand for RP-based fertiliser whilst increasing global food production, the Australasian research and extension priorities should include P-efficiency for economic and environmental reasons. Past fertiliser rates have necessarily exceeded P-removal, with the balance remaining in slowly available soil P. Where soil P now meets or exceeds critical agronomic values, a P-replacement strategy will bring economic and environmental benefits and deliver easy gains in on-farm P efficiency. While urgent for environmental reasons in intensive industries, where farm $\mathrm{P}$ balances are often strongly positive, this strategy also applies to broad-area industries wherever farmers don't base decisions on soil tests and fields are over-fertilised. Beyond balancing farm P budgets, the economic challenge is to draw down reserves of $P$ in soil or prevent further build-up, requiring plants to produce at lower critical-P concentrations. This might be achieved through more P-efficient genotypes or inoculants, but the practical advances from this type of research so far are minimal. The greatest long-term reduction in national $\mathrm{P}$ requirement may come with extensified farming systems and reduced P-intensive exports - nothing to do with 'Peak P' at all.
\end{abstract}

Keywords: peak phosphorus, phosphate rock, RP, P-efficiency

\section{Introduction}

In 2007/2008 the price of phosphate rock shot up $\sim 9$ fold from a long-term $\sim \mathrm{US} \$ 40 / \mathrm{t}$, only to quickly fall to under US\$100/t, finally settling at $\sim \mathrm{US} \$ 80 / \mathrm{t}$ as demand fell in response to rising fertiliser prices (Fig. 1), the addition of new production capacity, and the global financial crisis. The initial price hike appeared to vindicate predictions of 'Peak P' (Déry \& Anderson 2007). Some observers saw a parallel with the first oil crisis of the 1970s, regarding these price fluctuations as the harbinger of a looming crisis in $\mathrm{P}$ supply for agriculture. Sections of the media latched onto the story (see Business, Timesonline June 23, 2008), and even a Scientific American headline screamed: "Phosphorus: A Looming Crisis" (Vaccari 2009). A later more circumspect but widely reported Peak $\mathrm{P}$ analysis also concluded that $\mathrm{P}$ was running out (Cordell et al. 2009).

Apart from the obvious long-term question of resource stewardship to sustain human life on Earth, the prospect of Peak P raises several critical shorterterm questions for agronomists: (i) Is the reserve of high grade RP diminishing so fast that a shortage of $\mathrm{P}$ or a related price rise going to impact on food security in the foreseeable future; (ii) If there is an imperative for agriculture to manage with reduced inputs of $\mathrm{P}$ derived from RP, then how might that be achieved; (iii) Is improved P-efficiency (variously defined) really needed to ensure food security in coming decades, or should the immediate focus be on reducing costs and

Figure 1 Long-term on-farm price of P-fertiliser (USA, indexed to 1982).

Source: USDA (2010) Economic Research Service, Fertilizer Use and Price, Table 8

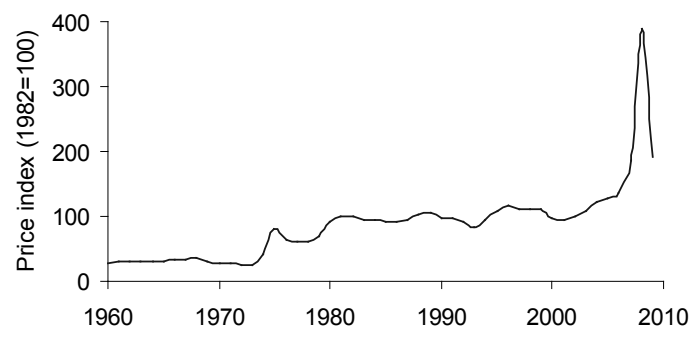


any environmental impacts resulting from excessive $\mathrm{P}$ use; and (iv) What are the implications for Australasian agriculture as distinct from global agriculture?

This review addresses the above questions from an agronomist's perspective, recognising that $\mathrm{P}$ futures ultimately need to be considered within the context of global stocks and flows of $\mathrm{P}$ beyond the farm (Cordell et al. 2009). However, I largely avoid the use of effluent and sewage as a source of $\mathrm{P}$, a big topic in its own right. I also want to acknowledge the work of many New Zealand and Australian scientists who for decades have sought improved $\mathrm{P}$ efficiency, mindful that $\mathrm{P}$ reserves are finite and that $\mathrm{P}$ is non-substitutable and practically non-renewable. Contributors to Reviews in Rural Science 3 (Blair 1976) from both Australia and New Zealand gave leadership in this area long before it was fashionable. In 1989, a group met in Canberra to review the options for improving genotypic $\mathrm{P}$ efficiency. Aspects of $\mathrm{P}$ efficiency were the subject of a Special Issue of Crop and Pasture Science (Cornish 2009b) arising from a workshop held before the price spike of 2008.

\section{Demand for $P$, $P$ supply and phosphate- rock reserves, and food security Demand}

The price shock of 2008 resulted from a confluence of events affecting demand (including population growth, shrinking world grain stocks and rapidly rising demand for vegetable oils for biofuels) plus pressure on supply from temporary fertiliser factory closures and China imposing a $135 \%$ tax on $\mathrm{P}$ exports. Some observers argued that the key factor behind the shock was rising demand for food, especially meat, in the developing world. Grain reserves may be restocked and the gloss fade on biofuels, with their expected area being $<4 \%$ arable area in 2030 (International Energy Agency, World Energy Outlook 2006), but other underlying forces will remain. Changes in national fertiliser use over the past 20-30 years make it difficult to predict future demand, which in developing countries now far exceeds the developed world (Table 1).
In most developed countries, P-fertiliser use has fallen over 30 years, although there are regional differences (Fig. 2). The EU and the USA together make up almost $80 \%$ of $\mathrm{P}$ demand by developed economies.

Australian demand peaked at $\sim 500 \mathrm{kt} \mathrm{P}$ in 1998 and has more or less fallen since, to $<400 \mathrm{kt} /$ year ( $3 \%$ of global use - $\mathrm{N}$ is only $1 \%$ ). Stable or declining demand for $\mathrm{P}$ in developed economies presumably reflects past use of high rates of P, meaning less is needed now, together with rising environmental concerns about $\mathrm{P}$ in runoff associated with excessive $\mathrm{P}$ in soils (the Water Framework Directive mandates reduced applications of $P$ in many areas in the EU). In Western Europe, large inputs of animal waste are reducing fertiliser demand. Improved technology for fertiliser management has also played a part, enabling farmers to use $\mathrm{P}$ more efficiently and increase farm output without increasing fertiliser inputs (discussed below). Vitousek et al. (2009) contend that nutrient application rates in developed economies have followed a trajectory over time from too little added nutrients to too much, and then to a more balanced fertiliser regime. Excess in the middle period may be more apparent than real if some of the $\mathrm{P}$ applied is necessarily 'lost' to sparingly available soil-P fractions.

In developing countries, $\mathrm{P}$ use has increased fivefold in the last 20 years, reflecting lower soil fertility due to previously inadequate fertiliser use, rising food requirement, changing diets and the economic capacity to apply more fertiliser. That rate of increase over the next 20 years would critically stress the capacity to supply fertiliser P, but such a trajectory is unlikely. Forecasters agree that fertiliser demand will continue to grow in the developing economies, although the forecasts are short-term and inconsistent. FAO (2008) predicted global consumption to rise by $2 \%$ pa until 2012 (Table 2). Most forecasts indicate growth of $\sim 2 \%$ in East Asia/SE Asia, 4\% in South Asia and Latin America, and for the developed world to remain stable or perhaps continue a slow decline. An earlier, detailed longer-term prediction (Steen 1998), which has so far been close to the mark, was for $2 \%$ growth to $\sim 2030$,

Table 1 World use of P-fertiliser in 2007 - selected countries (kt P).

\begin{tabular}{lclr}
\hline Developed & & Developing & \\
USA & 1690 & East Asia & 6232 \\
EU & 1990 & South Asia & 2830 \\
Australia & 432 & West Asia & 581 \\
New Zealand & 169 & Latin America (mainly Brazil) & 2433 \\
& & Africa & 431 \\
Total & 4851 & Total & 12140 \\
World total & & $16991^{1}$ & \\
\hline
\end{tabular}

Source: International Fertilizer Association, updated Feb. 2010

111 Mt P in 1976 (Lazenby 1976). P use has grown less than population. 
Table 2 Predicted change in P-fertiliser consumption (2008-2012).

\begin{tabular}{lcc}
\hline Region/sub region & $\begin{array}{c}\text { Share of world } \\
\text { consumption (\%) }\end{array}$ & $\begin{array}{c}\text { Annual } \\
\text { change (\%) }\end{array}$ \\
\hline World & 100 & 2.0 \\
Africa & 2.5 & 1.0 \\
North America & 12.0 & 0.5 \\
Latin America & 13.0 & 2.8 \\
West Asia & 3.3 & 1.0 \\
South Asia & 20.5 & 3.5 \\
East Asia & 36.1 & 1.9 \\
Western Europe & 5.6 & -0.7 \\
Eastern Europe & 2.0 & 4.5 \\
Oceania & 3.5 & 1.7 \\
\hline
\end{tabular}

Source: FAO (2008) World fertilizer trends and Outlook to 2012

reaching a plateau at $30 \mathrm{Mt} \mathrm{P} / \mathrm{yr}$ by 2040 . Steen assumed application rates would be high initially in developing countries but then decline, similarly to Vitousek et al. (2009) who noted that the pattern of fertiliser use seen in developed countries is being played out in China where fertiliser use is presently highly inefficient. The problem appears to be recognised in China (e.g. Romheld et al. 2005), so we will see if fertiliser rates start to fall in time.

Irrigated India is following the same trajectory as China. In both, subsidies and/or policies encourage over-fertilisation. India is reviewing its policies, but it would be unfortunate if support were cut to marginal farmers who are mostly in rainfed areas where productivity growth is essential to meet future food requirements (the role of the Rainfed Authority of India). Some sub-Saharan African countries are considering subsidies, which could see a much-needed increase in their P use. I think it is likely that over the coming decades it will be increasing $\mathrm{P}$ application in Africa and rainfed South Asia and China that will drive any increase in $\mathrm{P}$ demand, not irrigated agriculture
Figure 2 Fertiliser-P consumption in agriculture in the EU, USA and Australia (2007 only).

(Source: European Fertilizer Manufacturers Association, USDA).

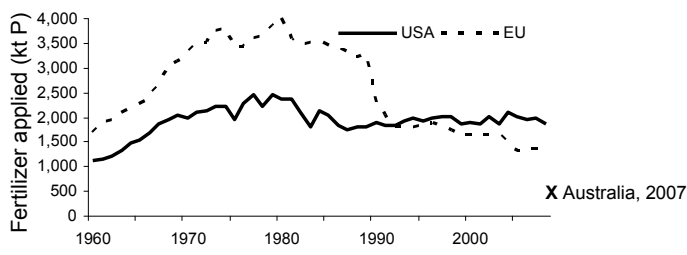

as many commentators suppose. Internationally, the greatest yield gaps (actual versus potential) are in rainfed areas, where increased $\mathrm{P}$ application will be of most benefit. The greatest excesses in fertiliser use are in irrigated areas where reduced $P$ provides environmental and economic benefits and production can be further intensified without necessarily putting on more $P$.

Larger-scale recycling of $\mathrm{P}$ from sewage will dampen demand for RP as new extraction technology comes on-line, making recycling more competitive. Much research has focused on struvite crystallisation $\left(\mathrm{MgNH}_{4} \mathrm{PO}_{4}\right.$ - for struvite chemistry and an Australian rural application see Ali et al. 2003). Note that whilst much greater recycling of $\mathrm{P}$ from human excreta may be a global imperative in the longer term, it won't help Australia and New Zealand to balance their national P budgets because so much of the agricultural production is exported. Of course, struvite or other P-recovery products may be imported. Hence, the prediction of future $\mathrm{P}$ and RP demand obviously needs to consider more than a simplistic analysis of local/world food needs and estimates of the RP-based fertiliser required to make up any yield gap due to $\mathrm{P}$ deficiency.

\section{Supplies of $R P$}

There are two aspects to the supply situation: (i) the production capacity to mine and process the RP into fertiliser and (ii) the size of the resource itself, in

Table 3 Phosphate mine production in 2008, reserve and reserve base (Mt)..$^{1,4}$

\begin{tabular}{|c|c|c|c|c|c|}
\hline & $\begin{array}{c}\text { Mine } \\
\text { production }\end{array}$ & Reserves & Reserve Base & Reserve life & $\begin{array}{c}\text { Reserve base } \\
\text { life }\end{array}$ \\
\hline Morocco/Western Sahara & 28.0 & 5700 & 21000 & 207 & 764 \\
\hline China & 50.0 & $4100^{2}$ & 10000 & 86 & 210 \\
\hline United States & 30.9 & 1220 & 3400 & 40 & 112 \\
\hline South Africa & 2.4 & 1500 & 2500 & 605 & 1008 \\
\hline Jordan & 5.5 & 900 & 1700 & 163 & 308 \\
\hline Australia & 2.3 & 82 & 1200 & 36 & 533 \\
\hline World & 167 & $15000^{3}$ & 47000 & 93 & 291 \\
\hline
\end{tabular}

'Source: US Geological Survey 2009; IFIA

${ }^{2}$ Author's note - there seems to be a view that this value may be greatly over-estimated.

${ }^{3}$ This estimate has been as high as 18000 in the past 5 years.

${ }^{4} \mathrm{~A}$ new 'preliminary' estimate from IFDC says reserves may be $4 \mathrm{x}$ greater than in Table 3 (Kauwenbergh 2010). 
Figure 3 Indicative peak phosphorus production (assuming $13 \% \mathrm{P}$ in RP).

Source: Cordell et al. 2009 Historical mine production $\sim 882$ Mt $\mathrm{P}(1900-2007)$, total under curve $3240 \mathrm{Mt}$. USGS data.

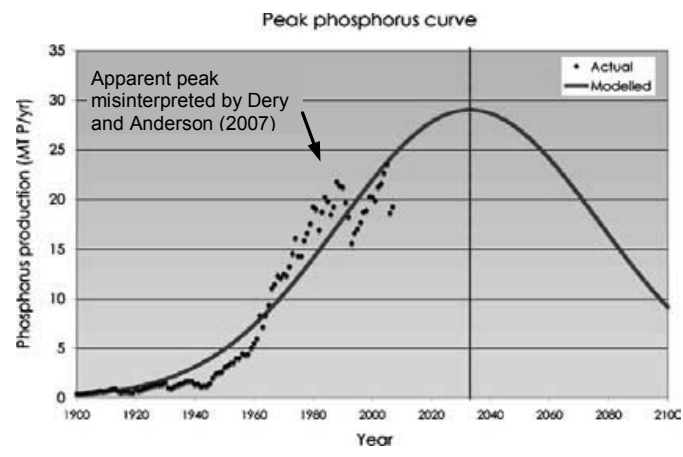

particular the economically minable reserve. The price spike of 2007/2008 had nothing to do with a shortage of reserves and much to do with mining and processing capacity (von Horn \& Sartorius 2009), which has now been corrected.

\section{Supply - the production capacity}

Global mine production of RP was $167 \mathrm{Mt}$ in 2008, or around $22 \mathrm{Mt}$ of elemental P assuming an average 13\% P. There is currently (2010) a small over-supply of RP, and there is no evident reason why mine production and processing capacity won't continue to expand in line with demand, at least in the medium-term (say 20 years). Worldwide RP mine production capacity is expected to increase through to 2013 to $>215 \mathrm{Mt} /$ year (27 Mt P), 20- 30\% more than in 2008 (IFA 2010; US Geological Survey 2010). New mines are scheduled to open in Australia and Peru in 2010 and Namibia and Saudi Arabia in 2011. Expansions to existing operations are planned in Brazil, China, Egypt, Finland, Morocco, Russia, and Tunisia. In Canada, a significant RP deposit in Northern Ontario is being evaluated for development, and another deposit in British Columbia is being investigated (USGS 2010). Although global supplies are expected to be adequate, this does not rule out regional deficits or geo-politically uncertainty.

\section{Supply-the size of the reserve}

Whether RP supplies meet demand beyond the next 20 years depends on the size of the reserve. This is hard to assess, as there are many definitions for what constitutes a reserve, and not all the data are reliable or necessarily available. The USGS defines 'reserve' as deposits that are economic to mine with current technology (exploitable at a cost $<$ US\$ 35/t). The 'reserve base' includes deposits with a 'reasonable potential for becoming economically available within planning horizons beyond those that assume proven technology and current economics' (exploitable at $<$ US\$ 100/t). $\mathrm{RP}$ in the reserve base may be less accessible, higher in contaminants (expensive to process) or have lower $\mathrm{P}$ concentration. A combination of sources indicates current reserves are $\sim 15000 \mathrm{Mt}$ RP (Table 3), but this estimate varies from year to year. Estimates of the reserve base also vary, but are in the order of $3-4 x$ the current reserve.

The largest deposits are in Africa, China, the Middle East and the USA. Australia holds most Oceania reserves ( $\sim 0.4 \%$ of global reserves). South Asia has no useful reserves and US reserves will be exhausted within a few decades. Of the total reserve, $40 \%$ is controlled by Morocco which raises concerns for possible future geo-political tension. Manufacture of sulfuric acid used in P-fertiliser production is largely confined to the developed world and China, further increasing the risk of geo-political tension over the supply and price of fertiliser. Estimates of the RP reserve continue to increase so prediction of reserve life based on currently known reserves is risky. The price rise of 2007/2008 spawned much exploration and serious consideration of marine deposits as potential RP sources. It would be surprising if estimates of world reserves didn't increase with further exploration and improvements in processing technology.

\section{Supply - the price of RP}

The quality of known deposits is falling, so rising processing costs are putting upward pressure on $\mathrm{P}$ fertiliser prices. However, the predicted price of RP is only in the range US $\$ 100-120 / t$ by 2030 (presumably indexed to 2009) (von Horn \& Sartorius 2009). If so, then neither rising prices nor reduced supply (see above) are likely to threaten food security or even farm profitability within the next 20-30 years. But future short-term price/supply problems can't be ruled out, as events of 2007/2008 show.

\section{How long will the RP reserves last?}

Concern about the life of reserves is not new. The simplest assessment, made annually by USGS, divides the reserve by the annual mine production, to produce the figures in the second-last column in Table 3 that predict current reserves will be depleted by 2100 ; and the reserve base within 300 yrs. These predictions take no account of important factors that could change demand and supply. Analysts at the USGS and Bureau of Mines modelled various scenarios and concluded pessimistically that "presently known (economic) reserves will be depleted within about 50 years and the remainder of the reserve base will be depleted within the next 100 years", unless the demand for $\mathrm{P}$ is reduced 
(Herring \& Fantel 1993). More sophisticated approaches (Steen 1998) have taken into account population trends, dietary changes and assumed improvements in fertiliser-use efficiency as well as changing economics of mining, predicting a plateau in global demand at $\sim 30$ Mt P/year (230 Mt RP at $13 \% \mathrm{P}$ ) by 2040 . This value is about the rate of mine production expected by 2013. Of course, the key question is 'for how long can this rate of mine production be maintained'. Steen estimated that if the world reserve (1996) was $23000 \mathrm{Mt}$, then half would be depleted by the mid $21^{\text {st }}$ century in the 'most likely' demand scenario. She notes reserves should "last for at least $100+$ years". The value used by Steen for the size of the reserve is $50 \%$ greater than the USGS 2007 estimate (Table 3) but the difference is not due to consumption. She used the median value from a range of sources, in effect deeming a small fraction of what the USGS calls the reserve base to be reserves.

\section{Concept of 'Peak P'}

The analytical approach known as 'Peak P' is an extension of 'Peak oil' (Hubbert 1949). Predictions are based on observations that extractive industries grow exponentially early in development but production begins to fall later when it gets harder and harder to get the resource. So the resource becomes a constraint to users long before it actually runs out. A critical assumption is that the peak supply of a resource is reached when half the total reserve remains in the ground. To predict "Peak P" (the peak rate and date of extraction), a Gaussian (bell-shaped) curve is fitted to the data for annual extraction, with the estimated total resource (depleted + remaining) under the curve. If the total reserve is known then the future date of 'peak P' can be predicted from mine production to the present. Alternatively, if 'Peak P' has been reached then the date of $\mathrm{P}$ depletion of the resource may be predicted. No assumptions are made about the demand for the reserve. 'Hubbert linearisation' attempts to predict both the size of the P reserve and the date of peak P. All of the peak $P$ analyses use current reserves, not the larger reserve base or revised IFDC estimate (Table 3 ).

The first 'Peak P' analysis predicted mine production would cease by $\sim 2050$ (Déry \& Anderson 2007). It was soon discredited when RP production in 2008 (167 Mt) exceeded what they assumed was the peak in 1990 $(150 \mathrm{Mt})$ - concrete plans are in place for production to exceed $210 \mathrm{Mt} / \mathrm{yr}$ by 2013 . The unduly pessimistic forecast was based on the incorrect assumption that reserves constrained RP production in the 1990s (Fig. 3 arrow), when other forces were at work. A recent, widely publicised Peak $\mathrm{P}$ analysis predicts peak production of $\sim 223 \mathrm{Mt} \mathrm{RP}(29 \mathrm{Mt} \mathrm{P}$ ) around 2033, when half the total resource will have been depleted (Fig. 3) (Cordell et al.
2009). This is only $31 \%$ of the remaining reserve, so the value is not comparable with the other estimates, but in Peak P analysis it signals when resource extraction inevitably declines. At the peak rate of $\mathrm{P}$ production, $50 \%$ depletion of the remaining reserve will occur around 2050, much as Steen predicted. Predicted 'Peak P' would of course be later if reserves of $23000 \mathrm{Mt}$ (Steen 1998) were used rather than the conservative estimate of $18000 \mathrm{Mt}$ (2 $358 \mathrm{Mt} \mathrm{P}$ ). Or much later with the revised IFDC estimates.

Is it neo-Malthusian to predict an end to reserves, or will market forces defer the problem by bringing on-line ever more production capacity? Whether the forecasting approach accounts for population growth and changing technology (Steen 1998) or not (USGS 2009, Table 3; Cordell et al. 2009), the predictions broadly agree that $P$ reserves that are currently economic to mine will effectively run out around the end of the century, preceded by a period of increasing scarcity and price. We have seen that demand will rise over the next 2-3 decades then stabilise at around $30 \mathrm{Mt} / \mathrm{yr}$ and possibly fall as global population stabilises ( $\sim 9$ billion by 2060 ), soil P rises in developing countries, fertiliser use becomes more efficient and recycling reduces demand for RP-based fertiliser. Additionally, RP supply will increase as new reserves are discovered and rising prices and new technology make it economic to mine the 'reserve base'. Hence, we can most likely expect a prolonged "demand plateau" rather than a "peak" in P supply. However, as Vaccari (2009) observes, "given the stakes, we should not leave our future to chance." In response to the question posed in the Introduction, 'yes', there is a case for agriculture to manage with reduced inputs of $\mathrm{P}$ derived from $\mathrm{RP}$.

If we are to reduce the global demand for RP by improving P-use efficiency, where are the big 'losses' we can do something about? According to Cordell et al. (2008), 'losses' in human waste account for $<10 \%$ of the global $\mathrm{P}$ budget ${ }^{1}$, so even $100 \%$ recycling will do little to balance the budget, as important as recycling may $b^{2}$. Big on-farm losses occur in applying animal waste to non-arable land (24\%), although some $\mathrm{P}$ is returned via grazing, and through erosion and runoff $(27 \%)^{3}$ on arable land. Cordell et al. (2008) say that improved fertiliser efficiency will decrease global demand for RP, but they point only generally to 'precision agriculture' and approaches that 'increase soil-P availability'. Hence, there is a need to tease out some of the thinking behind P-efficiency and suggest where it might be improved through agronomic management - most commentators aspire to the minimal aim of a balanced long-term farm $\mathrm{P}$ balance (Syers et al. 2008). 


\section{The agronomic response to 'Peak $\mathbf{P}$ '4}

Long-term use of fertiliser has raised the organic and inorganic P status of most soils above their native state with inputs necessarily exceeding outputs because soluble P fertilisers are readily "fixed" as adsorbed P, sparingly-soluble precipitates of $\mathrm{P}$ and as organic $\mathrm{P}$ which is recalcitrant to mineralisation. Only $10-20 \%$ of applied $\mathrm{P}$ is used in the year of application in most Australian soils. Subsequent use of the residual P rarely exceeds 50\% (Bolland \& Gilkes 1998; Bünemann et al. 2005; Holford 1997). The rest is in forms that are widely regarded as 'unavailable', although Syers et al. (2008) point out that fertiliser-P recovery can be up to $90 \%$ over appropriate timescales. The available $\mathrm{P}$ in agricultural soils now lies on a continuum between deficiency for agricultural plants through to and above critical concentrations for economic production, at which point it should be possible to balance P inputs with outputs or even draw down the reserve (Syers et al. 2008). On any field or farm, the strategy to improve $P$ efficiency depends on its $\mathrm{P}$ status and related economic and environmental considerations.

\section{Environmental considerations (with economic consequences)}

Environmentally driven actions to reduce $\mathrm{P}$ inputs are needed for soils with $\mathrm{P}$ well above the agronomic threshold, soils that increase the risk of 'leaking' $P$ to the environment (NLWA 2001). Soil-P thresholds for environmental risk appear to be higher than for agronomic response (Cornish unpublished) except for soils with the lowest $\mathrm{P}$ buffer index (PBI). Dairying and intensive horticulture typically have strongly positive farm and/or field $\mathrm{P}$ balances, resulting in soil $\mathrm{P}$ well above the agronomic threshold and runoff with elevated P concentrations (Nash \& Murdoch 1997; Baginska et al. 1998; Hollinger et al. 2001). Hence, there are economic and environmental reasons to cut fertiliser use. Addressing over-use of $P$ inputs in these intensive industries should be the first and by far the easiest way to reduce the national and farm/crop demand for $P$.

Excessive use of $\mathrm{P}$ is not confined to intensive industries. Notwithstanding the NLWA (2001) finding that soil $\mathrm{P}$ is low-marginal in many agricultural regions in Australia, recent work shows that over half of all broad-area crop and pasture soils have bicarbonate-P concentrations above critical values (except soils with lowest PBI) - yet these farms have a positive P-balance (D. Weaver \& M. Wong pers. comm.). ${ }^{5}$ Excessive P use in arable systems is not the same environmental risk as intensive agriculture because soil $\mathrm{P}$ is typically much lower, but still it makes no economic sense to apply fertiliser in excess of plant requirements when soil is at or above the critical value. Surprisingly, the Weaver $\&$ Wong survey found that many farmers who test for P do not appear to base their decisions on the results as there was much evidence of over-fertilisation. Hence, multidisciplinary research is needed that will lead to wider soil P testing and use in decision-making.

In the ideal situation, where farms have balanced $P$ budgets and soil $\mathrm{P}$ is near the critical concentration, agronomic $\mathrm{P}$ efficiency $\left(\right.$ Yield $_{(+\mathrm{P})}-$ Yield $\left._{(-\mathrm{P})} / \mathrm{P}_{\text {applied }}\right)$ is low and $P$-balance efficiency $\left(\mathrm{P}_{\text {output }} / \mathrm{P}_{\text {input (applied) }}\right)$ over time is high. Studies of farm-gate $\mathrm{P}$ balances by Weaver \& Wong suggest that few Australian farms are 'efficient', for reasons that are not always clear. This warrants further research. It should be noted that it is one thing to have a balanced farm $\mathrm{P}$ budget and quite another to have a balanced budget and optimal soil $\mathrm{P}$ on all parts of all fields - that is the future of precision or 'more-precise' agriculture.

\section{Further economic considerations and the quest for $P$ efficiency}

The main economic arguments for improving P-efficiency are that: (i) residual slowly available P is an asset, perhaps averaging $100 \mathrm{~kg} \mathrm{P} / \mathrm{ha}$ in arable land in Australia (Cornish 2009) (worth $\sim \$ 300 / \mathrm{ha}$ ), prompting many farmers to ask how they can access their asset and cut fertiliser costs (relevant where soil $\mathrm{P}$ is near critical values); and (ii), fertiliser costs may be cut by reducing P 'losses' to the slowly available pool (for soils below critical values). Both strategies rely on managing interactions between pools of $\mathrm{P}$ and retaining less $\mathrm{P}$ in the slowly-available pool (Fig. 4). Both offer short-term economic benefits. However, neither produces long-term improvement in the farm $\mathrm{P}$ balance, or national demand for $\mathrm{P}$, since (i) a negative $\mathrm{P}$ balance

1 Based on RP input of $17.5 \mathrm{Mt}$ and inputs from apparently un-fertilised grazing land of $12.1 \mathrm{Mt}$ (soil $\mathrm{P}$ being depleted).

2 Safe, effective strategies for using P recovered from human excreta will reduce global demand for RP but are not considered here.

3 Soil-conserving tillage can reduce erosion to $\leq 3 \mathrm{t} / \mathrm{ha}$, approaching soil formation rates. This need not be considered further here.

${ }^{4}$ My discussion draws on Syers et al. (2008), Cornish (2009b) and papers in the Special Issue of Crop and Pasture Science 60 .

5 NLWA (2001) highlight negative farm gate P balances in northern Australia and especially in the northern grains region. 
Figure 4 Conceptual framework to consider reduced dependency on RP-based fertiliser at farm scale.

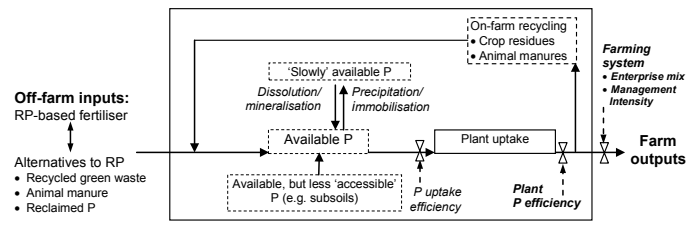

Boxes with broken lines denote $\mathrm{P}$ stocks, solid lines denote flows. Bold italic text denotes where farm farm-level P efficiency can be improved. Uptake efficiency includes genetic and agronomic methods.

cannot indefinitely draw down slowly available $\mathrm{P}$ and maintain output and (ii) reducing P losses to the slowly available pool improves efficiency only until up to the critical P concentration for the particular soil/farming system. Improved internal recycling will also improve P efficiency in the short term, but only until all soils on a farm are at the agronomic threshold. Agronomy may increase output per unit input and give an economic benefit (e.g. by deep placement), but not reduce longterm demand for $\mathrm{P}$.

The only way to reduce $\mathrm{P}$ input to a farm in the long-term is to output product that is lower in P (e.g. wheat with low $\mathrm{P}$ harvest index or a change to products that are lower in P) or export less product (Fig. 4). Some farmers appear to be successful with low-input 'pasture cropping', a system that is both less intensive than conventional mixed farming systems and exports relatively more low-P product (wool, meat) than grain (Cornish 2009a). These changes may occur in future for economic or agro-ecological reasons that have nothing directly to do with P-efficiency. Of the mechanisms under genetic control, only an appropriate physiological plant $\mathrm{P}$ efficiency will deliver long-term change in farm $\mathrm{P}$ efficiency. From the extensive research on this subject, only selection for low phytate grain appears to show any promise, and even here the end result is lower phytate rather than lower total $\mathrm{P}$ in the grain (Bowen et al. 2006).

The Special Issue of Crop and Pasture Science 60 (2) details strategies to improve P efficiency. Most focus on improving $\mathrm{P}$ uptake efficiency or modifying roots to either explore greater soil volumes or access lessavailable forms of $\mathrm{P}$ (including microbial inoculants). None of these strategies yet allows high production from low-P soils, or allows farmers to reduce their P inputs significantly, but some may give farmers confidence to cut fertiliser rates once soil $\mathrm{P}$ has been built up. My impression is that advances in practice have been minimal except in subsistence agriculture. However, there are promising leads for reducing the strength of immobilisation and McLaughlin (pers. comm.) sees benefit in revisiting deeper P-placement.

\section{Improving soil P testing}

Reliable soil testing underpins most strategies for improved P management. It is easy to criticise farmers for not using soil tests more but I suspect they lack confidence in soil testing (and associated advisory services). To a degree, this attitude is justified. Graphs of soil $\mathrm{P}$ versus crop or pasture yield ( $\%$ max) never come near the 'ideal', always showing variation that leads to uncertainty in the interpretation of soil test values (cf. Figs. 2 and 3 in Gourley et al. 2009). There are many reasons for this variation. In Australia the least-appreciated reason may be the interaction between water and P, so I would invest research funds in this direction as well as work with farmers to make better use of tools they already have, including soil tests and test strips. Dry surface soils have long been known to reduce uptake of soil $\mathrm{P}$ and increase fertiliser requirement (e.g. Cornish \& Myers 1977), yet this matter is rarely considered when making fertiliser recommendations. The consequences of this interaction for subsoil $\mathrm{P}$ and future $P$ requirements have been demonstrated recently.

\section{Conclusions on where to improve P- efficiency}

Easy gains in national P-efficiency can be found by not fertilising where it is environmentally risky, mindful that the soil-P threshold for environmental risk is generally greater than for agronomic response. Where soil $\mathrm{P}$ is near the agronomic threshold, farmers should aim to balance $\mathrm{P}$ outputs and inputs. Issues here include the apparent low use of soil testing to inform fertiliser decisions, uncertainty about critical values for specific sites/plants, and the inherent riskiness of reducing $\mathrm{P}$ inputs. Strategies to improve access to slowly available soil $\mathrm{P}$ won't deliver a miracle but they may give farmers greater assurance to reduce $\mathrm{P}$-fertiliser.

\section{REFERENCES}

Ali, M.I.; Schneider, P.A.; Hudson, N. 2003. Assessing nutrient recovery from piggery effluents. MODSIM03 NZ

Baginska, B.; Cornish, P.S.; Hollinger, E.; Kuczera, G.; Jones, D. 1998. Nutrient export from rural land in the Hawkesbury-Nepean catchment. In: Proceedings of the 9th Australian Agronomy Conference, Wagga Wagga, pp. 53-56.

Bowen, D.E.; Guttieri, M.J.; Peterson, K.; Raboy, V.; Souza, E.J. 2006. Phosphorus fractions in developing seeds of four low-phytate barley (H. vulgare L.) genotypes. Crop Science 46: 2468-2473.

Bolland, M.D.A.; Gilkes, R.J. 1998. The chemistry and agronomic effectiveness of phosphate fertilizers. Journal of Crop Production 1: 139-163.

Blair, G.J. 1976. Prospects for improving efficiency of phosphorus utilisation. In: Reviews in Rural Science III. UNE August 1976, 180 pp. 
Bünemann, E.K.; Heenan, D.P.; Marschner, P.; McNeill, A.M. 2006. Long-term effects of crop rotation, stubble management and tillage on soil phosphorus dynamics. Australian Journal of Soil Research 44: 611-618.

Cordell, D.; Drangert, Jan-Olof; White, S. 2009. The story of phosphorus: Global food security and food for thought. Global Environmental Change 19: 292-305.

Cornish, P.S. 2009a. Phosphorus management of organic and low-input farms. Crop and Pasture Science 60: 105-115.

Cornish, P.S. 2009b. Research directions: Improving plant uptake of soil phosphorus, and reducing dependency on input of phosphorus fertilizer. Crop and Pasture Science 60: 190-196.

Déry, P.; Anderson, B. 2007. Peak phosphorus. Energy Bulletin. August, 2007 energybulletin.net/ node/33164

Gourley, C.J.P.; Melland, A.; Waller, R.; Awty, I.; Smith, A.P.; Peverill, K.; Hannah, M. 2009. Making better fertiliser decisions for grazed pastures in Australia. Department of Primary Industries, Victoria.

Herring, J.R.; Fantel, R.J. 2003. Phosphate rock demand into the next century: Impact on world food supply. Natural Resources Research 2: 226-246.

Holford, I.R. 1997. Soil phosphorus: its measurement, and its uptake by plants. Australian Journal of Soil Research 35: 227-240.

Hollinger, E.; Cornish, P.S.; Baginska, B.; Mann, R.; Kuczera, G. 2001. Farm-scale stormwater losses of sediment and nutrients from a market garden near Sydney. Agricultural Water Management 47: 227-241.
Hubbert, M.K. 1949. Energy from fossil fuels. Science 109: 103.

Kauwenbergh, S. 2010. World Phosphate Rock Reserves \& Resources. IFDC, September 2010.

Lazenby, A. 1976. Fertilizer resources and the sub and super philosophy. In: Reviews in Rural Science 3, Ed. Blair, G. (UNE) August 1976.

Nash, D.; Murdoch, C. 1997. Phosphorus in runoff from a fertile dairy pasture. Australian Journal of Soil Research 35: 419-429.

Romheld, V.; Doluschitz, R.; Zhang, F.; Jayakumar, R.; Wolff, M. 2005. Eds. ERSEC Ecological Book Series - 1. 'Resource Management for Sustainable Intensive Agricultural Systems' (Tsinghua University Press, Beiging and Springer), ISBN 7-302-11579-6.

Steen, I. 1998. Phosphorus availability in the $21 \mathrm{st}$ century: Management of a non-renewable resource. Phosphorus and Potassium 217: 25-31.

Syers, J.K.; Johnston, A.E.; Curtin, D. 2008. Efficiency of soil and fertilizer phosphorus use. FAO Fertilizer and Plant Nutrition Bulletin 18, Rome, 2008.

Vaccari, D.A. 2009. Phosphorus: A Looming Crisis. Scientific American, June 2009: 54-59.

Vitousek, P.M.; Naylor, R.; Crews, T.; David, M.B. 2009. Nutrient imbalances in agricultural development. Science 324: 1519-1520.

Von Horn, J.; Sartorius, C. 2009. International Conference on nutrient recovery from wastewater streams. Eds. Ashley, K.; Mavinic, D.; Koch, F. ISBN: 9781843392323 (IWA Publishing, London UK) 